See Article page 1828.

\section{Commentary: Paradoxical increase in areas of myocardial fibrosis following septal myectomy}

\author{
Anita Nguyen, MBBS, MS
}

Septal myectomy in patients with obstructive hypertrophic cardiomyopathy abolishes left ventricular outflow tract obstruction and systolic anterior motion of the mitral valve, thereby alleviating symptoms in a majority of patients. Previous studies have demonstrated that septal myectomy improves left atrial volume and left ventricular mass. ${ }^{1,2}$ Tang and colleagues ${ }^{3}$ retrospectively reviewed 507 patients with obstructive hypertrophic cardiomyopathy who underwent septal myectomy at their institution, and demonstrate that although left atrial volume did not increase significantly following myectomy, left atrial ejection fraction improved. Their results further corroborate previous findings that myectomy enhances left ventricular mass, but how these echocardiographic parameters affect outcomes, including survival, remains to be established.

Late gadolinium enhancement is measured on cardiac magnetic resonance imaging, and increased late gadolinium enhancement has been associated with higher risk of adverse events, including ventricular arrhythmias and sudden cardiac death. ${ }^{4}$ There is no consensus on whether areas of high enhancement need to be removed surgically or whether resection of these areas decreases risks of sudden cardiac death or improves survival. Tang and colleagues ${ }^{3}$ further describe the outcomes of a subcohort of 57 patients who underwent both pre- and postoperative cardiac magnetic resonance imaging. An unexpected observation from their study was that late gadolinium enhancement increased significantly following myectomy. The authors postulate that extensive fibrosis may be responsible for residual

\footnotetext{
From the Department of Cardiovascular Surgery, Mayo Clinic, Rochester, Minn Disclosures: The author reported no conflicts of interest.

The Journal policy requires editors and reviewers to disclose conflicts of interest and to decline handling or reviewing manuscripts for which they may have a conflict of interest. The editors and reviewers of this article have no conflicts of interest.

Received for publication June 24, 2020; revisions received June 24, 2020; accepted for publication June 25, 2020; available ahead of print July 15, 2020.

Address for reprints: Anita Nguyen, MBBS, MS, Department of Cardiovascular Surgery, Mayo Clinic, 200 First St, SW, Rochester, MN 55905 (E-mail: nguyen. anita@mayo.edu).

J Thorac Cardiovasc Surg 2022;163:1835

$0022-5223 / \$ 36.00$

Copyright (C) 2020 by The American Association for Thoracic Surgery

https://doi.org/10.1016/j.jtcvs.2020.06.118
}

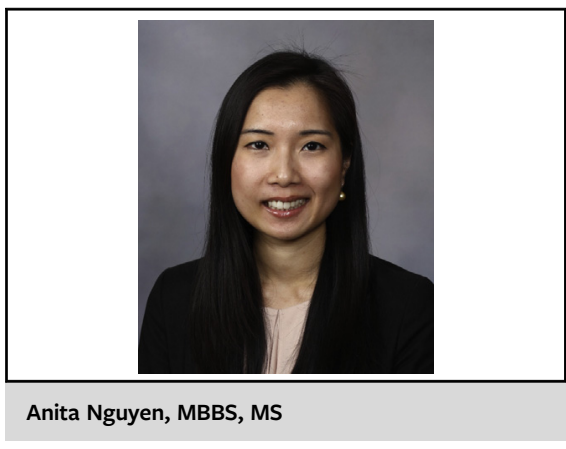

CENTRAL MESSAGE

Septal myectomy causes a paradoxical increase in myocardial fibrosis.

adverse events, including sudden cardiac death in patients who have undergone septal myectomy. It is possible that septal myectomy alone does not alter the natural progression of existing areas of myocardial fibrosis, and that resection of these areas is necessary to further decrease risks of adverse postoperative events. However, prospective studies whereby patients undergo regular pre- and postoperative cardiac magnetic resonance imaging are needed to further elucidate whether targeted resection of areas of fibrosis is beneficial for patients undergoing septal myectomy.

\section{References}

1. Nguyen A, Schaff HV, Nishimura RA, Dearani JA, Geske JB, Lahr BD, et al. Determinants of reverse remodeling of the left atrium after transaortic myectomy. Ann Thorac Surg. 2018;106:447-53.

2. Deb SJ, Schaff HV, Dearani JA, Nishimura RA, Ommen SR. Septal myectomy results in regression of left ventricular hypertrophy in patients with hypertrophic obstructive cardiomyopathy. Ann Thorac Surg. 2004;78:2118-22.

3. Tang B, Song Y, Yang Q, Cui H, Ji K, Zhao S, et al. Changes in left atrial function, left ventricle remodeling, and fibrosis after septal myectomy for obstructive hypertrophic cardiomyopathy. J Thorac Cardiovasc Surg. 2022;163:1828-34.e4.

4. Mentias A, Raeisi-Giglou P, Smedira NG, Feng K, Sato K, Wazni O, et al. Late gadolinium enhancement in patients with hypertrophic cardiomyopathy and preserved systolic function. J Am Coll Cardiol. 2018;72:857-70. 